\title{
Left atrial longitudinal strain by speckle tracking echocardiography correlates well with left ventricular filling pressures in patients with heart failure
}

\author{
Matteo Cameli*1, Matteo Lisi', Sergio Mondillo', Margherita Padeletti1, Piercarlo Ballo2, Charilaos Tsioulpas³, \\ Sonia Bernazzali and Massimo Maccherini ${ }^{3}$
}

\begin{abstract}
Background: The combination of early transmitral inflow velocity and mitral annular tissue Doppler imaging (E/Em ratio) is widely applied to noninvasively estimate left ventricular (LV) filling pressures. However E/Em ratio has a significant gray zone and its accuracy in patients with heart failure is debated. Left atrial (LA) deformation analysis by speckle tracking echocardiography (STE) was recently proposed as an alternative approach to estimate LV filling pressures. This study aimed at exploring the correlation of LA longitudinal function by STE and Doppler measurements with direct measurements of $L V$ filling pressures in patients with heart failure.

Methods: A total of 36 patients with advanced systolic heart failure (ejection fraction $\leq 35 \%$ ), undergoing right heart catheterization, were studied. Simultaneously to pulmonary capillary wedge pressure (PCWP) determination, peak atrial longitudinal strain (PALS) and mean E/Em ratio were measured in all subjects by two independent operators. PALS values were obtained by averaging all segments (global PALS), and by separately averaging segments measured in the 4-chamber and 2-chamber views.
\end{abstract}

Results: Not significant correlation was found between mean E/Em ratio and PCWP ( $R=0.15)$. A close negative correlation between global PALS and the PCWP was found $(R=-0.81, p<0.0001)$. Furthermore, global PALS demonstrated the highest diagnostic accuracy (AUC of 0.93) and excellent sensitivity and specificity of 100\% and 93\%, respectively, to predict elevated filling pressure using a cutoff value less than 15.1\%. Bland-Altman analysis confirmed this close agreement between PCWP estimated by global PALS and invasive PCWP (mean bias $0.1 \pm 8.0 \mathrm{mmHg}$ ).

Conclusion: In a group of patients with advanced systolic heart failure, E/Em ratio correlated poorly with invasively obtained LV filling pressures. However, LA longitudinal deformation analysis by STE correlated well with PCWP, providing a better estimation of LV filling pressures in this particular clinical setting.

\section{Background}

Accurate noninvasive estimation of left ventricular (LV) filling pressures is a clinical valuable tool to predict the severity of different heart diseases and to decide therapeutic strategy, particularly in patients with heart failure [1]. In fact, invasive capillary wedge pressure (PCWP) measurement, a surrogate for LV filling pressures, is directly associated with functional capacity and progno-

\footnotetext{
* Correspondence: cameli@cheapnet.it

1 Department of Cardiovascular Diseases, University of Siena, Siena, Italy Full list of author information is available at the end of the article
}

sis in patients with heart failure [2-4]. Several echocardiographic indices have been proposed to assess LV filling pressures. In particular, early transmitral flow velocity (E) combined with mitral annular early diastolic velocity (Em) derived from tissue Doppler imaging (E/Em ratio) has been shown to correlate with PCWP in a wide range of cardiac patients [5-9]. However E/Em ratio has a significant gray zone $[5,7,10]$ and its accuracy, particularly when applied in patients with heart failure, is debated $[11,12]$. Speckle tracking echocardiography (STE) is a novel non-Doppler-based method for the angle-indepen- 
dent and objective quantification of myocardial deformation from standard bidimensional datasets [13-16]; in contrast to Doppler-derived indexes, speckle tracking has the advantage of being angle-independent, and to be less affected by reverberations, side lobes and drop out artifacts. STE has recently evolved and, enabling the quantification of longitudinal myocardial left atrial (LA) deformation dynamics, it was recently proposed as an alternative approach for the LV filling pressure estimation[17]. Therefore this study aimed at exploring the utility of these Doppler and LA STE derived echocardiographic indices in predicting LV filling pressures in consecutive patients with systolic heart failure undergoing right heart catheterization.

\section{Methods}

\section{Study population}

Forty-eight consecutive patients with symptomatic chronic (> 6 months) systolic heart failure (ejection fraction $\leq 35 \%$ and New York Heart Association class III to IV symptoms), who underwent a right heart catheterization, in the cardiac catheterization laboratory $(\mathrm{n}=34)$ or in the intensive care unit $(\mathrm{n}=14)$, because of concerns about hemodynamic derangements and/or to a staging of patients listed for heart transplantation, were enrolled. All were in sinus rhythm, hemodinamically stable and had simultaneous right heart catheterization and transthoracic echocardiographic imaging. A previous cardiac resynchronization therapy with defibrillator (CRT-D) was not an exclusion criteria. Patients were excluded if they had nonsinus rhythm, mechanical ventilation, severe mitral regurgitation, any mitral stenosis, any prosthetic mitral and/or aortic valve, heart transplantation or an insufficient imaging quality of the LA endocardial border. All subjects gave their written informed consent for the participation to the study. All work was in compliance with the declaration of Helsinki and it was performed with the approval of local ethics committee.

\section{Cardiac catheterization}

Readings of invasive cardiac pressure measurements were performed by an investigator blinded to all echocardiographic data. The pressure transducers were balanced before data acquisition with the zero level at mid-axillary line. Pulmonary artery (PA) catheters were used to measure PA pressures, mean right atrial pressure and mean PCWP. The wedge position was verified by fluoroscopy, phasic changes in pressure waveforms and oxygen saturation. Cardiac output and cardiac index were derived by the thermodilution technique (average of 5 cardiac cycles with $<10 \%$ variation) and by the Fick equation through sampling of a mixed central venous blood gas taken in the pulmonary artery and of an arterial blood gas.

\section{Standard echocardiography}

Echocardiographic studies were performed using a portable echocardiograph (Vivid i, GE, USA), equipped with a $2.5 \mathrm{MHz}$ transducer. Subjects were studied in a supine position during the heart catheterization. Measurements of left ventricular and left atrial dimensions, LV ejection fraction, and diastolic LV filling velocities were made in accordance with current recommendations of ASE [18]. LV ejection fraction, measured using Simpson's method, was used as a standard index of global LV systolic function. The ratio between peak early (E) and late (A) diastolic LV filling velocities was used as standard indices of LV diastolic function [19]. LA volumes were measured using the area-length method, from the apical four and two chamber views. LA volumes were subsequently indexed by body surface area (BSA). The time interval between the onset of the QRS on the electrocardiogram and the aortic and mitral valve opening and closure were measured using pulsed-wave Doppler from the LV outflow and inflow, respectively.

\section{Tissue Doppler Imaging}

LV longitudinal function was explored by pulsed Tissue Doppler imaging, placing the sample volume at the level of mitral lateral and septal annulus from the apical fourchamber view [20]. Mean peak systolic (Sm), early diastolic (Em), and late diastolic (Am) annular velocities were obtained by averaging respective values measured at the septal and lateral sides of the mitral annulus. Mean $\mathrm{Em}$ and the derived mean $\mathrm{Em} / \mathrm{Am}$ ratio were used as load-independent markers of ventricular diastolic relaxation [21]. Mean E/Em ratio was also calculated [7].

\section{Speckle Tracking Echocardiography}

For speckle tracking analysis, apical four- and two-chamber views images were obtained using conventional two dimensional gray scale echocardiography, during breath hold and with a stable ECG recording. Care was taken to obtain true apical images using standard anatomic landmarks in each view and not foreshorten the left atrium, allowing a more reliable delineation of the atrial endocardial border. We also avoided visualization of the LA appendage in the apical 2-chamber view to minimize its effect on LA strain measurements. Three consecutive heart cycles were recorded and averaged. The frame rate was set between 60 and 80 frames per second.

The analysis of files recorded was performed off-line by a single experienced and independent echocardiographer, who was not directly involved in the image acquisition and had no knowledge of hemodynamic mesasurements, using a commercially available semi-automated twodimensional strain software (EchoPac, GE, USA). As previously described [13], LA endocardial border is manually traced in both four- and two-chamber views, thus delin- 
eating a region of interest (ROI), composed by 6 segments. Then, after the segmental tracking quality analysis and the eventual manual adjustment of the ROI, the longitudinal strain curves are generated by the software for each atrial segment. As shown in Figure 1, peak atrial longitudinal strain (PALS), measured at the end of the reservoir phase, was calculated by averaging values observed in all LA segments (global PALS), and by separately averaging values observed in 4- and 2-chamber views (4- and 2-chamber average PALS, respectively). The time to peak longitudinal strain (TPLS) was also measured as the average of all 12 segments (global TPLS) and by separately averaging values observed in the two apical views (4- and 2 -chamber average TPLS). In patients in whom some segments were excluded because of the impossibility of achieving adequate tracking, PALS and TPLS were calculated by averaging values measured in the remaining segments.

\section{Reproducibility}

To assess the reproducibility of global PALS, 10 patients were randomly selected: Bland-Altman analysis was performed to evaluate the intra- and interobserver agreement by repeating the analysis 1 week later by the same observer and a second independent observer. Bland-Altman analysis demonstrated good intra- and interobserver agreement, with small bias not significantly different from zero. Mean differences \pm 2 standard deviations were $0.4 \pm 2.1 \%$ and $0.6 \pm 3.4 \%$, for intra- and interobserver agreement, respectively.

\section{Statistical analysis}

Data are shown as mean \pm SD. A P value $<0.05$ was considered statistically significant. Pearson's correlation coefficients were calculated to assess the relationships

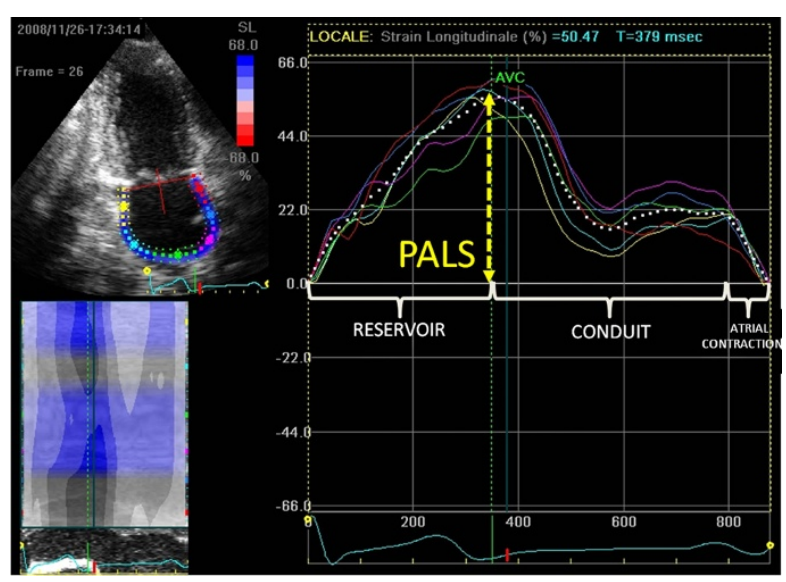

Figure 1 Measurement of peak atrial longitudinal strain (PALS) from an apical two-chamber view. The dashed curve represents the average atrial longitudinal strain along the cardiac cycle. (PALS, peak atrial longitudinal strain; AVC, aortic valve closure). between continuous variables. On the basis of similar previous studies [22-25], a PCWP value of $18 \mathrm{mmHg}$ was chosen as the cutoff value. Sensitivity and specificity were calculated using standard definitions, receiver operating characteristic curves were constructed and the area under the curve was calculated for the prediction of PCWP $\geq 18 \mathrm{mmHg}$. The agreement between different methods was assessed with the method of Bland and Altman [26]. Analyses were performed using the SPSS (Statistical Package for the Social Sciences, Chicago, Illinois) software Release 12.0.

\section{Results}

\section{Patients characteristics}

Of 48 patients screened, 36 patients ( 15 women, 21 men) met eligibility criteria during the study period. The admitting diagnosis were coronary artery disease (29 patients) and non-ischemic cardiomiopathy (7 patients). All patients were classified as New York Heart Association class III to IV with a mean LV ejection fraction of $26.1 \pm 5 \%$. Five were excluded for nonsinus rythm; 3 , for severe mitral valve disease, 3 for poor echocardiographic window; and 2, for difficulties in heart catheterization. Table 1 shows the clinical, echocardiographic and catheterization data between the 15 patients with $\mathrm{PCWP}<18$ $\mathrm{mmHg}$ and the 21 patients with PCWP $\geq 18 \mathrm{mmHg}$. As listed in Table 1, there were no significant differences in such characteristics as age, hypertension, diabetes, blood pressure, heart rate, presence of coronary artery disease and medical therapy between patients with $\mathrm{PCWP}<18$ $\mathrm{mmHg}$ and $\geq 18 \mathrm{mmHg}$. Patients with previous CRT-D implant were all in spontaneous sinus rhythm and were equally distributed in the two groups.

\section{Invasive hemodynamic and echocardiographic measurements}

Conventional Doppler and tissue-Doppler indices showed increased mitral E $(99.4 \pm 46 \mathrm{~cm} / \mathrm{s}$ vs $82.6 \pm 33$ $\mathrm{cm} / \mathrm{s}, \mathrm{p}<0.001)$, mitral $\mathrm{E} / \mathrm{A}$ ratio (3.66 \pm 1.3 vs $2.19 \pm 1.1$, $\mathrm{p}<0.001)$ and mean E/Em ratio $(15.9 \pm 7.9$ vs $12.6 \pm 6.4$, $\mathrm{p}$ $=0.01$ ) in the patients with $\mathrm{PCWP} \geq 18 \mathrm{mmHg}$, instead no differences between groups were found for mitral Em. Regarding novel atrial STE measurements, among a total of 432 segments analyzed, the software was able to correctly track 411 (95.1\%) segments. Global PALS was significantly lower in patients with PCWP $\geq 18 \mathrm{mmHg}(9.8 \pm$ $4.2 \%$ vs $16.9 \pm 4.0 \%, \mathrm{p}<0.001)$. Similar results were obtained in PALS measured in four-chamber view (8.0 \pm $3.6 \%$ vs $14.3 \pm 3.8 \%, \mathrm{p}<0.001)$ and in two-chamber view $(11.2 \pm 4.5 \%$ vs $18.0 \pm 4.6 \%, \mathrm{p}<0.001)$. No significant differences of TPLS values were detected between two groups. 
Table 1: Clinical, echocardiographic and catheterization data of the study population $(n=36)$

\begin{tabular}{|c|c|c|c|}
\hline & $\begin{array}{c}\text { PCWP }<18 \mathrm{mmHg} \\
(\mathrm{n}=15)\end{array}$ & $\begin{array}{c}\text { PCWP } \geq 18 \mathrm{mmHg} \\
(\mathrm{n}=21)\end{array}$ & p Value \\
\hline \multicolumn{4}{|l|}{ Clinical data } \\
\hline Age & $57.7 \pm 8.1$ & $57.3 \pm 8.6$ & 0.77 \\
\hline Gender (\% female) & 43.2 & 42.3 & 0.65 \\
\hline Body surface area $\left(\mathrm{m}^{2}\right)$ & $1.95 \pm 0.2$ & $1.94 \pm 0.2$ & 0.70 \\
\hline Hypertension & $20(89 \%)$ & $12(88 \%)$ & 0.66 \\
\hline Diabetes mellitus & $8(36 \%)$ & $5(35 \%)$ & 0.81 \\
\hline Hypercholesterolemia & $17(77 \%)$ & $10(75 \%)$ & 0.51 \\
\hline Current smoker & $2(9 \%)$ & $2(12 \%)$ & 0.44 \\
\hline Ischemic cause (\%) & $81 \%$ & $82 \%$ & 0.65 \\
\hline CRT-D & $4(28.6 \%)$ & $7(33.3 \%)$ & 0.21 \\
\hline \multicolumn{4}{|l|}{ Medical therapy } \\
\hline Ace-inhibitors or ARB & $10(66.6 \%)$ & $14(66.6 \%)$ & 0.81 \\
\hline Beta-blockers & $8(53.3 \%)$ & $11(52.3 \%)$ & 0.66 \\
\hline Spironolactone & $7(46.7 \%)$ & $9(42.8 \%)$ & 0.22 \\
\hline Loop diuretics & $13(86.7 \%)$ & $18(85.7)$ & 0.44 \\
\hline Statins & $9(60.0 \%)$ & $14(66.7 \%)$ & 0.32 \\
\hline \multicolumn{4}{|l|}{ Echocardiographic data } \\
\hline Left atrial area $\left(\mathrm{cm}^{2}\right)$ & $26.9 \pm 5.9$ & $33.1 \pm 6.6$ & 0.02 \\
\hline Left atrial volume indexed $\left(\mathrm{ml} / \mathrm{m}^{2}\right)$ & $30.2 \pm 9$ & $41.1 \pm 10.1$ & 0.009 \\
\hline End-diastolic LV diameter (mm) & $57.3 \pm 8.3$ & $63.0 \pm 8.0$ & 0.01 \\
\hline LV mass index $\left(\mathrm{g} / \mathrm{m}^{2}\right)$ & $116.6 \pm 31.3$ & $118.3 \pm 33.5$ & 0.21 \\
\hline LV Ejection Fraction (\%) & $26.5 \pm 3.5$ & $25.7 \pm 4.3$ & 0.15 \\
\hline Mitral E (cm/s) & $82.6 \pm 33$ & $99.4 \pm 46$ & $<0.001$ \\
\hline Mitral E/A ratio & $2.19 \pm 1.1$ & $3.66 \pm 1.3$ & $<0.001$ \\
\hline $\mathrm{Sm}(\mathrm{cm} / \mathrm{s})$ & $5.0 \pm 1.1$ & $5.0 \pm 1.2$ & 0.81 \\
\hline $\mathrm{Em}(\mathrm{cm} / \mathrm{s})$ & $6.6 \pm 1.8$ & $6.2 \pm 1.8$ & 0.24 \\
\hline $\mathrm{E} / \mathrm{Em}(\mathrm{cm} / \mathrm{s})$ & $12.6 \pm 6.4$ & $15.9 \pm 7.9$ & 0.01 \\
\hline Global PALS (\%) & $16.9 \pm 4.0$ & $9.8 \pm 4.2$ & $<0.001$ \\
\hline 4-chamber PALS (\%) & $14.3 \pm 3.8$ & $8.0 \pm 3.6$ & $<0.001$ \\
\hline 2-chamber PALS (\%) & $18.0 \pm 4.6$ & $11.2 \pm 4.5$ & $<0.001$ \\
\hline Global TPLS (ms) & $445 \pm 81$ & $410 \pm 78$ & 0.09 \\
\hline \multicolumn{4}{|l|}{ Catheterization data } \\
\hline Heart rate (bpm) & $73.3 \pm 15.3$ & $76.0 \pm 15.1$ & 0.20 \\
\hline Systolic blood pressure (mmHg) & $118 \pm 19$ & $116 \pm 21$ & 0.28 \\
\hline Diastolic blood pressure $(\mathrm{mmHg})$ & $79 \pm 11$ & $76 \pm 13$ & 0.27 \\
\hline Mean PAP (mmHg) & $21.8 \pm 7.8$ & $32.1 \pm 9.9$ & $<0.001$ \\
\hline PCWP $(\mathrm{mmHg})$ & $13.1 \pm 5.1$ & $23.8 \pm 7.4$ & $<0.001$ \\
\hline $\mathrm{Cl}$ therm $\left(\mathrm{ml} / \mathrm{min} / \mathrm{m}^{2}\right)$ & $2.12 \pm 0.7$ & $2.13 \pm 0.9$ & 0.40 \\
\hline Cl fick $\left(\mathrm{ml} / \mathrm{min} / \mathrm{m}^{2}\right)$ & $1.99 \pm 0.4$ & $1.97 \pm 0.4$ & 0.42 \\
\hline
\end{tabular}

(PCWP, Pulmonary capillary wedge pressure; CRT-D, previous cardiac resynchronization therapy with defibrillation implantion; $A C E$, angiotensinconverting enzyme; ARB, angiotensin receptor blocker; LV, left ventricular; E, early transmitral flow velocity; A, atrial transmitral flow velocity; Sm, systolic mitral annular velocity; Em, early diastolic mitral annular velocity; PALS, peak atrial longitudinal strain; TPLS, time-to-peak atrial longitudinal strain; PAP, pulmonary arterial pressure; $\mathrm{Cl}$ therm, cardiac index estimated by thermodilution; $\mathrm{Cl}$ fick, cardiac index estimated by the Fick equation.) 


\section{Correlation between echocardiographic and invasive measurements}

A strong inverse correlation was observed between PCWP and global PALS $(\mathrm{r}=-0.81 ; \mathrm{p}<0.0001)$ (Figure 2), instead no correlation was found with mean $\mathrm{E} / \mathrm{Em}$ ratio ( $\mathrm{r}$ $=0.15$ ) (Figure 3). Several other significant relations were noted between PCWP and LA volume indexed ( $\mathrm{r}=0.38$; $\mathrm{p}<0.01)$, LA area $(\mathrm{r}=0.33 ; \mathrm{p}=0.021)$, LV end-diastolic volume $(\mathrm{r}=0.23 ; \mathrm{p}=0.05)$ and Doppler (mitral $\mathrm{E}: \mathrm{r}=0.40$, $\mathrm{p}<0.01$; mitral E/A ratio: $\mathrm{r}=0.52$, $\mathrm{p}<0.001$ ) measurements. To better understand the limitation and the lack of correlation between mean E/Em ratio and PCWP in the study population, clinical, echocardiographic and hemodynamic variables were compared between two groups according to the presence or absence of concordant mitral E/Ea ratio $>15$ and PCWP $>18 \mathrm{~mm} \mathrm{Hg}$. Among all variables analyzed, LV ejection fraction, LV end-diastolic volume, LV end-diastolic diameter and cardiac index appeared statistically different between two groups; the group of patients with discordant E/Em and PCWP measurements presented larger LV dimensions and more impaired systolic function.

\section{Diagnostic accuracy of noninvasive estimate of elevated filling pressure}

To further investigate the value of these echocardiographic indices to predict an elevated filling pressure, we performed receiving operating characteristics (ROC) curve analyses. Area under the curve (AUC), optimal cutoff values and corresponding sensitivities and specificities to predict PCWP $18 \mathrm{mmHg}$ or greater are presented in Table 2. Among all echocardiographic parameters analyzed, global PALS showed the highest diagnostic accuracy $(\mathrm{AUC}=0.93)$ and excellent sensitivity and specificity of $100 \%$ and $93.2 \%$, respectively, to predict elevated filling

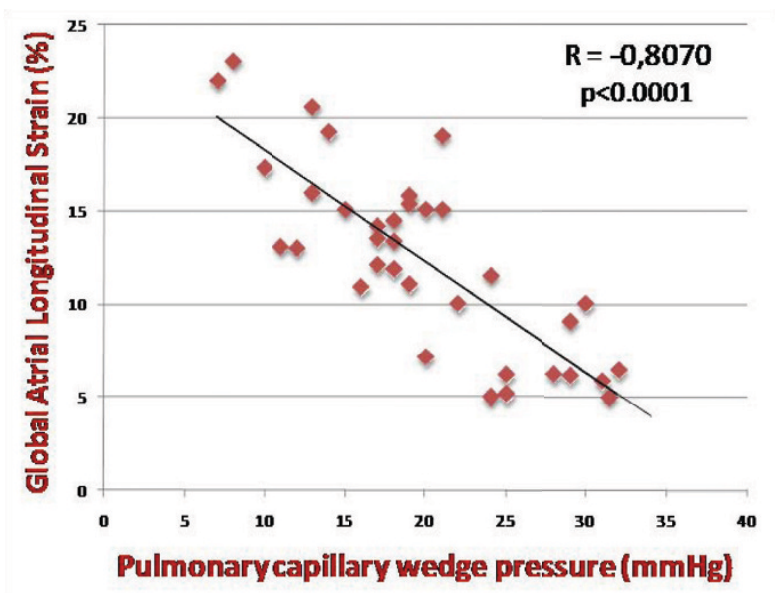

Figure 2 Correlation between global peak atrial longitudinal strain (PALS) and pulmonary capillary wedge pressure. $R=$ 0.8070; $p<0.0001$. (PALS, peak atrial longitudinal strain). pressure using a cutoff value less than $15.1 \%$. LA volume indexed presented weaker accuracy with an AUC of 0.78 and sensitivity and specificity of $67.9 \%$ and $87.5 \%$, respectively, at a cutoff value greater than $37.8 \mathrm{ml} / \mathrm{m}^{2}$. Mean E/ Em ratio presented limited diagnostic accuracy (AUC = 0.69) (Figure 4). Bland-Altman analysis comparing PCWP estimated by global PALS and invasive PCWP demonstrated a close agreement with a mean bias of $0.1 \pm$ $8.0 \mathrm{mmHg}$ (mean \pm 2 standard deviation) (Figure 5).

\section{Discussion}

In this study we analyzed for the first time the correlation with PCWP of a novel speckle tracking index, the LA longitudinal strain, comparing it with other Doppler indices, in particular the E/Em ratio, in patients with advanced systolic heart failure referred for right heart catheterization. Using simultaneous measured echocardiographic and invasive hemodynamic variables, we found in this particular group of patients a strong correlation between global PALS and PCWP, in contrast with the weaker and not significant correlation showed by mean $\mathrm{E} / \mathrm{Em}$ ratio. Furthermore, global PALS demonstrated the highest diagnostic accuracy (AUC of 0.93) and excellent sensitivity and specificity of $100 \%$ and $93 \%$, respectively, to predict elevated filling pressure using a cutoff value less than $15.1 \%$. ROC curve analysis indicated that, by using this cutoff value of $15.1 \%$, although the relative limited sample size, no one patient in the group of elevated PCWP was misdiagnosed. Bland-Altman analysis confirmed this close agreement between PCWP estimated by global PALS and invasive PCWP. The atrial reservoir phase is essential for LV filling by storing energy during ventricular systole, that is released after MV opening [27]; in our study the global PALS, parameter for the functional eval-

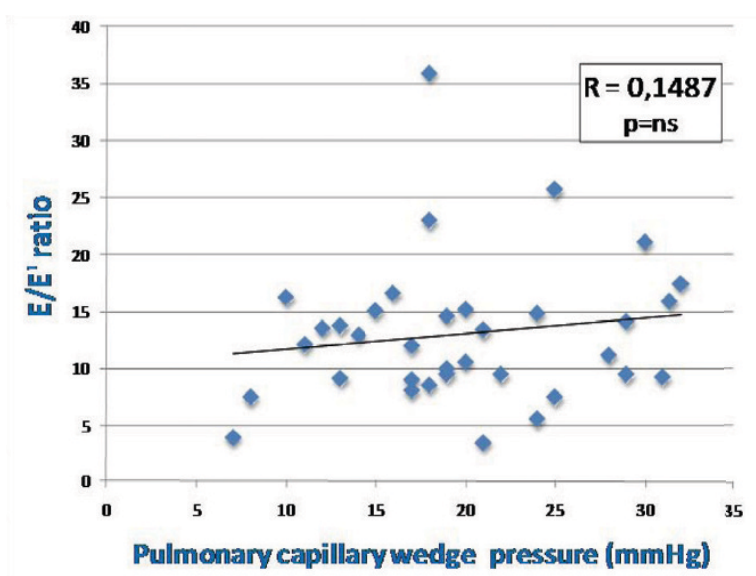

Figure 3 Correlation between global peak atrial longitudinal strain (PALS) and mean $E / E m$ ratio. $R=0.1487 ; p=n s$. (PALS, peak atrial longitudinal strain; E, early transmitral flow velocity; Em, early diastolic mitral annular velocity). 
Table 2: Receiver operating characteristics analysis of echocardiographic parameters to predict pulmonary capillary wedge pressure $\geq 18 \mathrm{mmHg}$

\begin{tabular}{|c|c|c|c|c|}
\hline & Cutoff value & $\begin{array}{l}\text { Sensitivity } \\
(95 \% \mathrm{CI})(\%)\end{array}$ & $\begin{array}{l}\text { Specificity } \\
(95 \% \mathrm{Cl})(\%)\end{array}$ & AUC \\
\hline \multicolumn{5}{|l|}{$\begin{array}{c}\text { Two-dimensional } \\
\text { Echo }\end{array}$} \\
\hline LV EDV & $>278 \mathrm{ml}$ & $50.0(15.6-85.6)$ & $88.2(46.3-99.6)$ & 0.60 \\
\hline LA area & $>36.5 \mathrm{~cm}^{2}$ & $60.0(32.4-84.1)$ & $50.0(16.1-85.3)$ & 0.68 \\
\hline $\begin{array}{l}\text { LA volume indexed } \\
\text { Mitral flow Dopple }\end{array}$ & $>37.8 \mathrm{ml} / \mathrm{m}^{2}$ & $67.9(53.9-96.8)$ & $87.5(56.9-95.7)$ & 0.78 \\
\hline Mitral E wave & $>94.2 \mathrm{~cm} / \mathrm{s}$ & $90.1(66.8-99.7)$ & $66.8(26.3-93.2)$ & 0.72 \\
\hline E/A ratio & $>2.6$ & $89.4(65.1-97.2)$ & $65.2(24.3-92.9)$ & 0.70 \\
\hline \multicolumn{5}{|l|}{ Tissue Doppler } \\
\hline \multicolumn{5}{|l|}{ Speckle tracking } \\
\hline Global PALS & $<15.1 \%$ & $100(83.9-100)$ & $93.2(78.1-99.8)$ & 0.93 \\
\hline
\end{tabular}

(AUC, Area under the curve; $\mathrm{Cl}$, confidence interval; LV, left ventricular; EDV, end diastolic volume; LA, left atrial; $\mathrm{E}$, early transmitral flow velocity; A. atrial transmitral flow velocity; Em, early diastolic mitral annular velocity; PALS, peak atrial longitudinal strain).

uation of the atrial reservoir phase (Figure 1), resulted progressively decreased with the augmentation of LV filling pressures. The potential mechanism of this inverse correlation could be explained by the principle that PCWP is the afterload of LA function; if PCWP is high, the left atrium should be chronically stressed, resulting in decrease of LA reservoir function and finally in remodeling with LA chamber dilation, as demonstrated in patients with heart failure [28].
Regarding Doppler indices, mitral E and E/A ratio were significantly higher in the patients with elevated PCWP, but their diagnostic accuracy were relatively poor (AUC of 0.72 and 0.70 , respectively). Similarly, mean E/Em ratio appeared unable to adequately predict elevated filling pressure (AUC of 0.69). According to our results, that are confirmed by previous studies [12,29-31], we did not confirm the previously reported finding that changes in the mitral E/Em ratio accurately track changes in PCWP in
Global PALS

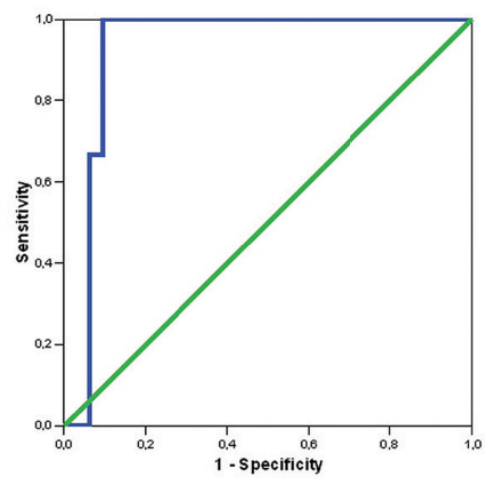

AUC 0.927
LA volume indexed

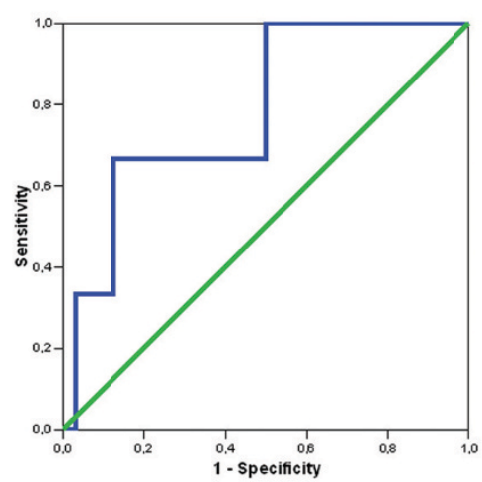

AUC 0.781
E/Em ratio

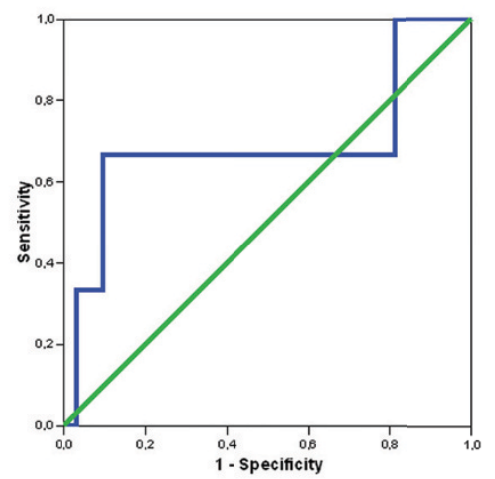

AUC 0.688

Figure 4 Diagnostic accuracy of noninvasive estimate of elevated filling pressure. Receiving operating characteristic (ROC) curves for global peak atrial longitudinal strain (PALS), left atrial (LA) volume indexed and mean E/Em ratio for prediction of pulmonary capillary wedge pressure $\geq 18$ $\mathrm{mmHg}$ in patients with advanced systolic heart failure. (PALS, peak atrial longitudinal strain; LA, left atrial; E, early transmitral flow velocity; Em, early diastolic mitral annular velocity; AUC, area under the curve). 


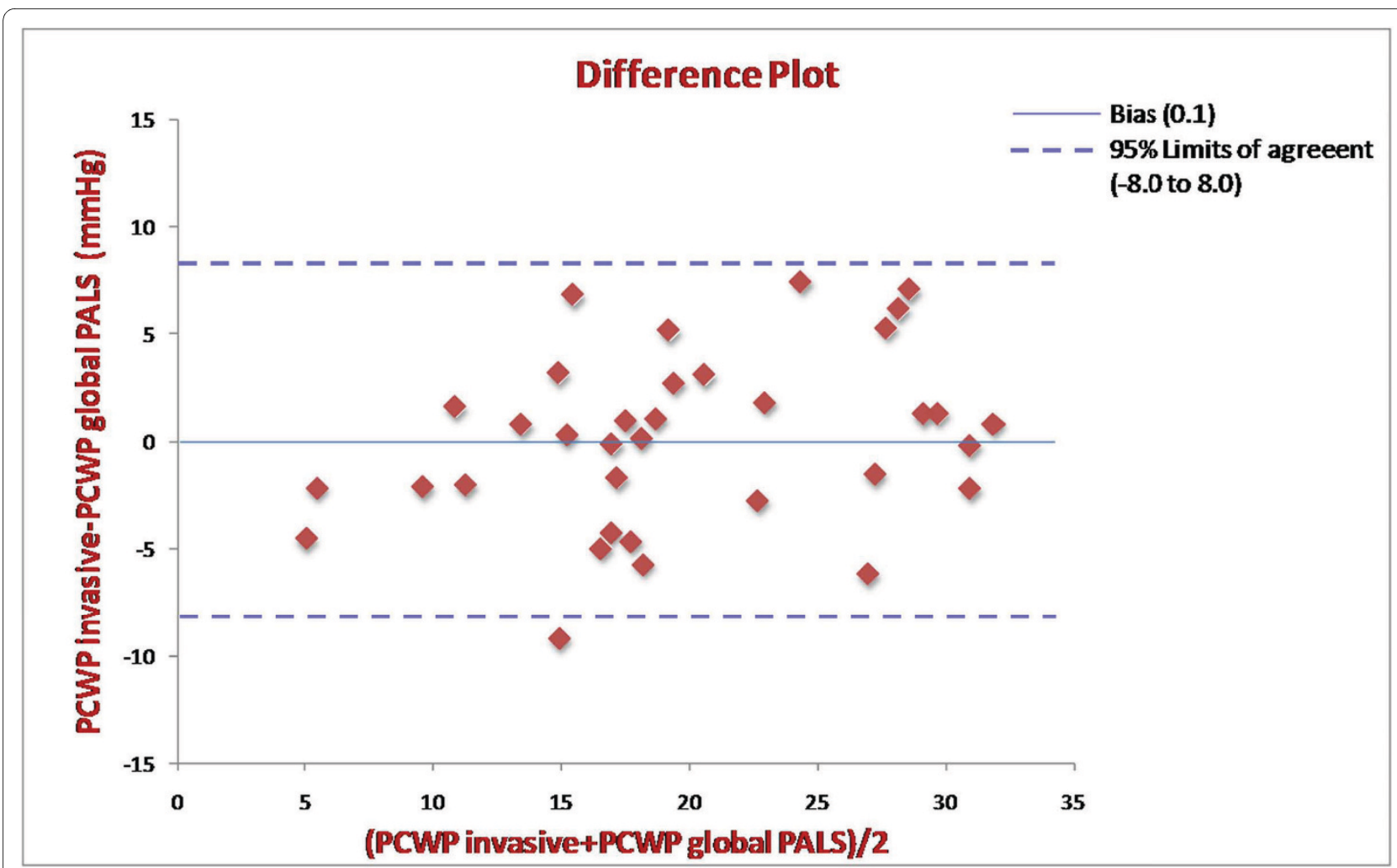

Figure 5 Bland-Altman analysis. Bland-Altman agreement plot comparing pulmonary papillary wedge pressure (PCWP) estimated by global peak atrial longitudinal strain (PALS) and invasive PCWP in the 36 patients. Bias (0.1); 95\% Limits of agreement (-8.0 to 8.0). (PALS, peak atrial longitudinal strain; PCWP, pulmonary capillary wedge pressure).

advanced systolic heart failure [10]. The lack of correlation between mean E/Em ratio and PCWP in our study, particularly evident in patients with larger LV volumes, more impaired cardiac indices, is probably due to the fact that patients with advanced heart failure often have severe LV fibrosis, stiffness and impaired cardiac systolic function, that could restrict systolic and subsequently early diastolic mitral excursion and affect mitral inflow velocity differently than expected, invalidating the $\mathrm{E} / \mathrm{Em}$ approach in this particular clinical setting.

\section{Limitations}

The measurement of global PALS requires more capability and is contingent on the presence of adequate apical views. However, in this study, which included supine patients on the cardiac catheterization table or in the intensive care unit, the feasibility was excellent at $94 \%$. Considered the close dependence of STE with the singlecardiac cycle strain analysis, it was not possible to conduct the study even in patients with non-sinus rhythm. Regional wall motion abnormalities in severely dilated and/or ischemic ventricles might have altered mitral Em acquisition. However, instead of analyzing only the septal or the lateral Em, we considered the average of both walls [32]. No invasive hemodynamic measurements of LA or
LV end-diastolic pressure were performed, considering that PCWP is accepted as a well validated surrogate [33,34].

Although there was a limited sample size, we were able to show novel findings. Nonetheless, larger prospective validation studies using these novel indices are of utmost importance.

\section{Conclusion}

In patients with advanced systolic heart failure mean E/ Em ratio may not be a useful index to estimate filling pressures; the measurement of global PALS, instead, provides a close prediction of PCWP and could be considered a promising noninvasive index to assess LV filling pressures in this particular clinical setting.

\section{Competing interests}

The authors declare that they have no competing interests.

\section{Authors' contributions}

MC, ML, MP, CT and SB were responsible for the collection of data; MC drafted the manuscript and performed the statistical analysis; SM and MM were responsible for the design of the study and revised the manuscript for important intellectual content. PC also revised the manuscript for important intellectual content. All authors read and approved the final manuscript. 


\section{Author Details}

'Department of Cardiovascular Diseases, University of Siena, Siena, Italy, ${ }^{2}$ Cardiology Operative Unit, S. Maria Annunziata Hospital, Firenze, Italy and ${ }^{3}$ Department of Cardiothoracic Surgery, University of Siena, Italy

Received: 17 March 2010 Accepted: 21 April 2010

Published: 21 April 2010

\section{References}

1. Oh JK: Echocardiography as a noninvasive Swan-Ganz catheter. Circulation 2005, 111:3192-3194.

2. Haskell RJ, French WI: Accuracy of left atrial and pulmonary artery wedge pressure in pure mitral regurgitation in predicting ventricular end-diastolic pressure. Am J Cardiol 1988, 61:136-141.

3. Keogh AM, Baron DW, Hikie JB: Prognostic guides in patients with idiopathic or ischemic dilated cardiomyopathy for cardiac transplantation. Am J Cardiol 1990, 65:903-908.

4. Stevenson WG, Stevenson LW, Middlekauff HR, Fonarow GC, Hamilton MA, Woo MA, Saxon LA, Natterson PD, Steimle A, Walden JA: Improving survival for patients with advanced heart failure: a study of 737 consecutive patients. J Am Coll Cardiol 1995, 26:1417-1423.

5. Nagueh SF, Middleton KJ, Kopelen HA, Zoghbi WA, Quinones MA: Doppler tissue imaging: a noninvasive technique for evaluation of left ventricular relaxation and estimation of filling pressures. J Am Coll Cardiol 1997, 30:1527-33.

6. Nagueh SF, Mikati I, Kopelen HA, Middleton KJ, Quinones MA, Zoghbi WA: Doppler estimation of left ventricular filling pressure in sinus tachycardia. Circulation 1998, 98:1644-1650.

7. Ommen SR, Nishimura RA, Appleton CP, Miller FA, Oh JK, Redfield MM, Tajik AJ: Clinical utility of Doppler echocardiography and tissue Doppler imaging in the estimation of left ventricular filling pressures: a comparative simultaneous Doppler-catheterization study. Circulation 2000, 102:1788-94.

8. Diwan A, McCulloch M, Lawrie GM, Reardon MJ, Nagueh SF: Doppler estimation of left ventricular filling pressures in patients with mitral valve disease. Circulation 2005, 111:3281-3289.

9. Nagueh SF, Lakkis NM, Middleton KJ, Spencer WH, Zoghbi WA, Quiñones MA: Doppler estimation of left ventricular filling pressures in patients with hypertrophic cardiomyopathy. Circulation 1999, 99:254-261.

10. Dokainish H, Zoghbi WA, Lakkis NM, Al-Bakshy F, Dhir M, Quinones MA, Nagueh SF: Optimal non-invasive assessment of LV filling pressures: a comparison of tissue Doppler echocardiography and BNP in patients with pulmonary artery catheters. Circulation 2004, 109:2432-2439.

11. Rivas-Gotz C, Manolios M, Thohan V, Nagueh SF: Impact of left ventricular ejection fraction on estimation of left ventricular filling pressures using tissue Doppler and flow propagation velocity. Am J Cardiol 2002, 91:780-784.

12. Mullens W, Borowski A, Curtin R, Thomas J, Tang W: Tissue Doppler imaging in the estimation of intracrdiac filling pressure in decompensated patients with advanced systolic heart failure. Circulation 2009, 119:62-70.

13. Cameli M, Caputo M, Mondillo S, Ballo P, Palmerini E, Lisi M, Marino E, Galderisi M: Feasibility and reference values of left atrial longitudinal strain imaging by two-dimensional speckle tracking. Cardiovascular Ultrasound 2009, 7:6.

14. Vianna-Pinton R, Moreno CA, Baxter CM, Lee KS, Tsang TS, Appleton CP: Two-Dimensional Speckle-Tracking Echocardiography of the Left Atrium: Feasibility and Regional Contraction and Relaxation Differences in Normal Subjects. J Am Soc Echocardiogr 2009, 22:299-305.

15. Kim DG, Lee KJ, Lee S, Jeong SY, Lee YS, Choi YJ, Yoon HS, Kim JH, Jeong KT, Park SC, Park M: Feasibility of two-dimensional global longitudinal strain and strain rate imaging for the assessment of left atrial function: a study in subjects with a low probability of cardiovascular disease and normal exercise capacity. Echocardiography 2009, 26:1179-87.

16. Saraiva RM, Demirkol S, Buakhamsri A, Greenberg N, Popoviæ ZB, Thomas $\mathrm{JD}$, Klein AL: Left atrial strain measured by two-dimensional speckle tracking represents a new tool to evaluate left atrial function. J Am SoC Echocardiogr 2010, 23:172-80.

17. Wakami K, Ohte N, Asada K, Fukuta H, Goto T, Mukai S, Narita H, Kimura G: Correlation between left ventricular end diastolic pressure and peak atrial wall strain during left ventricular systole. J Am Soc Echocardiogr 2009, 22:847-851.
18. Lang RM, Bierig M, Devereux RB, Flachskampf FA, Foster E, Pellikka PA, Picard MH, Roman MJ, Seward J, Shanewise JS, Solomon SD, Spencer KT, Sutton MS, Stewart WJ, Chamber Quantification Writing Group; American Society of Echocardiography's Guidelines and Standards Committee; European Association of Echocardiography: Recommendations for Chamber Quantification: A Report from the American Society of Echocardiography's Guidelines and Standards Committee and the Chamber Quantification Writing Group, Developed in Conjunction with the European Association of Echocardiography, a Branch of the European Society of Cardiology. J Am Soc Echocardiogr 2005, 18:1440-1463

19. Quinones MA, Otto CM, Stoddard M, Waggoner A, Zoghbi WA Recommendations for quantification of Doppler echocardiography: a report from the Doppler quantification Task force of the Nomenclature and Standards Committe of the American Society of

Echocardiography. J Am Soc Echocardiogr 2002, 15:167-184.

20. Yu CM, Sanderson JE, Marwick, Oh JK: Tissue Doppler imaging a new prognosticator for cardiovascular disease. J Am Coll Cardiol 2007, 49:1903-1914

21. Kasner M, Westermann D, Steendijk P, Gaub R, Wilkenshoff U, Weitmann $K$, Hoffmann W, Poller W, Schultheiss HP, Pauschinger M, Tschöpe C: Utility of Doppler echocardiography and tissue Doppler imaging in the estimation of diastolic function in heart failure with normal ejection fraction: a comparative Doppler-conductance catheterization study. Circulation 2007, 116:637-647.

22. Yamamuro M, Yoshida K, Hozumi T, Akasaka T, Takagi T, Kaji S, Kawamoto T, Yoshikawa J: Noninvasive Evaluation of Pulmonary Capillary Wedge Pressure in Patients With Acute Myocardial Infarction by Deceleration Time of Pulmonary Venous Flow Velocity in Diastole. J Am Coll Cardiol 1999, 34:90-94.

23. Hozumi T, Yoshida K, Mori I, Akasaka T, Takagi T, Kaji S, Kawamoto T, Ueda $Y$, Morioka S: Noninvasive assessment of hemodynamic subsets in patients with acute myocardial infarction using digital color Doppler velocity profile integration and pulmonary venous flow analysis. Am J Cardio/ 1999, 83:1027-32.

24. Givertz MM, Slawsky MT, Moraes DL, McIntyre KM, Colucci WS: Noninvasive determination of pulmonary artery wedge pressure in patients with chronic heart failure. Am J Cardiol 2001, 87:1213-5.

25. Vignon P, Aitssain A, François B, Preux PM, Pichon N, Clavel M, Frat JP, Gastinne H: Echocardiographic assessment of pulmonary artery occlusion pressure in ventilated patients: a transoesophageal study. Crit Care 2008, 12:R18.

26. Bland JM, Altman DG: Statistical methods for assessing agreement between two methods of clinical measurements. Lancet 1986, 1:307-310.

27. Grant C, Bunnell IL, Greene DG: The reservoir function of the left atrium during ventricular systole. an angiocardiographic study of atrial stroke volume and work. Am J Med 1964, 37:36-43.

28. Gottdiener JS, Kitzman DW, Aurigemma GP, Arnold AM, Manolio TA: Left atrial volume, geometry, and function in systolic and diastolic heart failure of persons $>$ or $=65$ years of age (the cardiovascular health study). Am J Cardiol 2006, 97:83-89.

29. Wang J, Khoury DS, Thohan V, Torre-Amione G, Naqueh SF: Global diastolic strain rate for the assessment of left ventricular relaxation and filling pressures. Circulation 2007, 115:1376-83.

30. Dokainish H, Sengupta R, Pillai M, Bobek J, Lakkis N: Usefulness of new diastolic strain and strain rate indexes for the estimation of left ventricular filling pressure. Am J Cardiol 2008, 101:1504-9.

31. Ten Brinke EA, Bertini M, Klautz RJ, Antoni ML, Holman ER, Veire NR van de, Bax JJ, Steendijk P: Noninvasive estimation of left ventricular filling pressures in patients with heart failure after surgical ventricular restoration and restrictive mitral annuloplasty. J Thorac Cardiovasc Surg 2010 in press.

32. Dokainish H: Combining tissue Doppler echocardiography and B-type natriuretic peptide in the evaluation of left ventricular filling pressures: review of the literature and clinical recommendations. Can J Cardiol 2007, 23:983-9.

33. Werko L, Varnauskas E, Elliasch H, Lagerlof H, Senning A, Thomasson B: Further evidence that the pulmonary capillary venous pressure pulse in man reflects cyclic pressure changes in the left atrium. Circ Res 1953, 1:337-339. 
34. Rahimtoola SH, Loeb HS, Ehsani A, Sinno MZ, Chuquimia R, Lal R, Rosen KM, Gunnar RM: Relationship of pulmonary artery to left ventricular diastolic pressures in acute myocardial infarction. Circulation 1972, 46:291-297.

doi: $10.1186 / 1476-7120-8-14$

Cite this article as: Cameli et al., Left atrial longitudinal strain by speckle tracking echocardiography correlates well with left ventricular filling pressures in patients with heart failure Cardiovascular Ultrasound 2010, 8:14

Submit your next manuscript to BioMed Central and take full advantage of:

- Convenient online submission

- Thorough peer review

- No space constraints or color figure charges

- Immediate publication on acceptance

- Inclusion in PubMed, CAS, Scopus and Google Scholar

- Research which is freely available for redistribution

Submit your manuscript at www.biomedcentral.com/submit
() BioMed Central 